\title{
PEMANFAATAN KULIT BAWANG MERAH SEBAGAI PEWARNA KAIN DENGAN TEKNIK JUMPUTAN MENGGUNAKAN MORDAN TAWAS, KAPUR, DAN TUNJUNG
}

\author{
Made Diah Angendari \\ Fakultas Teknik Dan Kejuruan, Universitas Pendidikan Ganesha \\ dekdiahku@yahoo.com
}

\begin{abstract}
Abstrak
Penelitian ini bertujuan untuk mengetahui: (1) hasil pewarnaan kain dengan teknik jumputan menggunakan zat warna kulit bawang tanpa proses mordating, (2) perbedaan hasil jadi pewarnaan kain teknik jumputan dengan kulit bawang merah dengan modan tawas, kapur, dan tunjung, (3) hasil jadi pewarnaan kain teknik jumputan dengan kulit bawang merah yang paling disukai antara menggunakan mordan tawas, kapur, dan tunjung.Jenis penelitian ini adalah penelitian eksperimen. Uji kualitas meliputi penilaian ketuaan warna dan tingkat kesukaan panelis. Peneliti menggunakan pengujian mutu hedonik, yaitu panelis diminta tanggapan tentang kesukaan produk hasil eksperimen. Analisis deskriptif untuk mengetahui gambaran tentang data yang diperoleh yaitu ketuaan warna. Uji statistik digunakan untuk menguji hipotesis.

Hasil penelitian adalah sebagai berikut: (1) Kulit bawang merah dapat digunakan sebagai bahan pewarna kain dengan teknik jumputan tanpa proses mordating. (2) Ada perbedaan hasil jadi pewarnaan kain teknik jumputan dengan kulit bawang merah dengan menggunakan mordan tawas, kapur, dan tunjung, tawas menghasilkan warna yang lebih muda, kapur sedang dan tunjung warna tua (3) Hasil jadi pewarnaan kain teknik jumputan dengan kulit bawang merah yang paling disukai antara menggunakan mordan tawas, kapur, dan tunjung adalah yang menggunakan mordan tawas.
\end{abstract}

Kata Kunci: Kulit Bawang Merah, Jumputan, Mordan Tawas, Kapur, Tunjung

\begin{abstract}
This study aims to determine: (1) the results of coloring cloth jumputan technique using onion skin dye without mordating process, (2) differences in the results so jumputan technique of coloring cloth with red onion skin with Modan alum, lime, and lotus, (3) results so jumputan technique of coloring cloth with red onion skin most preferably between using a mordant alum, lime, and lotus. This research is an experimental research. Test includes assessing the quality of aging and color preference level panelists. Researchers using hedonic quality testing, namely A panelist asked to comment on the results of experimental products. Descriptive analysis to know the description of the data obtained by the aging of color. Statistical tests were used to test the hypothesis.

The results of the study are as follows: (1) Skin onion can be used as a dye fabric with jumputan technique without mordating process. (2) There is a difference in the results so jumputan technique of coloring cloth with red onion skin using a mordant alum, lime, and lotus, alum resulted in lighter colors, lime medium and dark color lotus (3) The results so fabric dyeing technique jumputan with onion skins red most preferably between using mordant alum, lime, and lotus is the use of alum mordant.
\end{abstract}

Keywords: Skin Onion, Groovy, Mordan Tawas, Lime, Alas 


\section{PENDAHLUAN}

Tekstil di Indonesia berkembang sangat pesat. Hal ini ditandai dengan adanya bahan tekstil yang beragam tersedia di pasaran. Masyarakat memiliki kebebasan memilih jenis, warna dan motif yang diinginkan baik untuk bahan pakaian atau sebagai bahan lenan rumah tangga.

Pada awalnya proses pewarnaan tekstil menggunakan zat warna alam. Namun, seiring kemajuan teknologi dengan ditemukannya zat warna sintetis untuk tekstil maka semakin terkikislah penggunaan zat warna alam. Keunggulan zat warna sintetis adalah lebih mudah diperoleh, ketersediaan warna terjamin, jenis warna bermacam macam, dan lebih praktis dalam penggunaannya. Meskipun dewasa ini penggunaan zat warna alam telah tergeser oleh keberadaan zat warna sintesis namun penggunaan zat warna alam yang merupakan kekayaan budaya warisan nenek moyang masih tetap dijaga keberadaannya khususnya pada proses pembatikan, jumputan, pembuatan kain tradisional dan perancangan busana. Rancangan busana maupun kain batik dan jumputan yang menggunakan zat warna alam memiliki nilai jual atau nilai ekonomi yang tinggi karena memiliki nilai seni dan warna khas, ramah lingkungan sehingga berkesan etnik dan eksklusif.

Untuk memenuhi akan warna maka dilakukan proses pewarnaan. Pewarnaan dapat dilakukan melalui berbagai cara dan berbagai jenis bahan pewarna. Ditinjau dari asalnya terdapat pewarna alami dan pewarna buatan. Zat pewarna alami banyak digunakan untuk mewarnai bahan tradisional seperti batik, jumputan dan tenunan. Dalam perkembangannya bahan tradisional tersebut khusunya kain jumputan saat ini cenderung menggunakan bahan pewarna buatan (modern). Pemakaian bahan pewarna buatan ini karena beberapa alasan antara lain banyak tersedia di pasaran dan proses pewarnaan relatif mudah dan cepat. Namum bahan pewarna buatan memiliki kekurangan antara lain warna tidak tahan lama dan memiliki kandungan zat yang membahayakan kesehatan.
Zat warna sintesis dapat menimbulkan masalah bagi lingkungan juga berbahaya bagi kesehatan manusia. Dengan melihat dampak yang ditimbulkan oleh zat warna sintesis baik pada lingkungan maupun pada manusia, maka hal ini akan menyadarkan manusia untuk kembali mengunakan zat perwarna alam. Dengan gencarnya anjuran untuk mengurangi dampak lingkungan, penggunaan zat pewarna alami sangat dianjurkan.

$$
\text { Untuk itu, sebagai upaya }
$$

mengangkat kembali penggunaan zat warna alam untuk tekstil khususnya kain jumputan maka perlu dilakukan pengembangan zat warna alam dengan melakukan eksplorasi sumber-sumber zat warna alam dari potensi sumber daya alam Indonesia yang melimpah. Eksplorasi ini dimaksudkan untuk mengetahui secara kualitatif warna yang dihasilkan oleh berbagai tanaman di sekitar kita untuk pencelupan kain jumputan. Dengan demikian hasilnya dapat semakin memperkaya jenis-jenis tanaman sumber pewarna alam sehingga ketersediaan zat warna alam selalu terjaga dan variasi warna yang dihasilkan semakin beragam. Eksplorasi zat warna alam ini bisa diawali dari memilih berbagai jenis tanaman yang ada di sekitar kita baik dari bagian daun, bunga, batang, kulit ataupun akar.

Pada umumnya semua bahan alami misalnya bagian dari tanaman yang mengandung zat pewarna dapat digunakan sebagai bahan pewarna alami. Salah satu sumber daya alam yang dapat dipakai untuk zat warna alam adalah bawang merah (Allium cepa L) sebagai zat warna alternatif. Bagian dari tanaman ini yang dipakai sebagai zat warna alam adalah bagian kulit bawang merah. Kulit bawang merah mengandung zat warna alam yaitu senyawa antosianin dan flaponoida. Zat warna ini dapat diekstraksi dengan cara ekstraksi panas, dan larutan zat warna alam yang dihasilkan dapat dibuat menjadi zat warna dalam bentuk serbuk dengan proses penguapan. Zat warna yang dihasilkan dapat digunakan untuk proses pewarnaan pada bahan tekstil. Dalam hal 
ini digunakan kulit bawang merah limbah rumah tangga dan limbah setelah panen bawang merah yang selama ini kurang dimanfaatkan secara optimal dan dibuang percuma.

Salah satu kendala pewarnaan tekstil khususnya jumputan menggunakan zat warna alam adalah ketersediaan variasi warnanya sangat terbatas dan ketersediaan bahannya yang tidak siap pakai sehingga diperlukan proses-proses khusus untuk dapat dijadikan larutan pewarna tekstil. Begitu juga dengan kualitas warnanya yang cenderung berwarna muda.

Agar zat warna yang dipakain untuk mencelup memilki kekuatan/ketuaan warna yang baik maka perlu dilakukan proses fiksasi atau mordating yaitu untuk memcuci zat warna yang masuk ke dalam serat sehinga dapat menimbulkan daya tahan luntur warna. Zat yang dapat membangkitkan warna setelah bahan dicelup dengan zat warna kulit bawang merah adalaf zat fiksasi tawas, kapur dan tunjung. Pemakaian air tawas, kapur, dan tunjung sebagai pemangkit warna pada kain karena zat fiksator tersebut aman bagi lingkungan, mudah didapat, murah haganya serta terbukti dapat digunakan sebagai zat pembangkit warna. Permasalah yang timbul apakah ekstrak limbah kulit bawang merah dapat digunakan sebagai zat warna tekstil dan bagaimana pengaruh tawas, kapur, dan tunjung terhadap warna kain. Dalam proses pencelupan ini menggunakan media kain kapas. Kain kapas terbuat dari bahan baku serat kapas yang mempuyai struktur serat tersusun dari molekul-molekul selulosa. Bahan tekstil yang dapat diwarnai dengan zat warna alam adalah bahan tekstil yang terbuat dari serat selulosa karena berfifat higroskopis atau menyerap air.

Oleh karena itu penelitian ini mencoba untuk memanfaatkan kulit bawang merah kering sebagai pewarna pada kain dengan teknik jumputan mengunakan mordan tawas, kapur, dan tunjung sehingga dicari: (1) warna yang dihasilkan pada pewarnaan kain dengan teknik jumputan menggunakan zat warna kulit bawang merah tanpa proses mordatin, (2) warna yang dihasilkan pada pencelupan kain dengan teknik jumputan menggunakan zat warna kulit bawang merah menggunakan mordan tawas, kapur dan tunjung dan (3) hasil jadi pewarnaan dengan kulit bawang merah yang paling disukai antara menggunakan mordan tawas, kapur, dan tunjung.

\section{METODE PENELITIAN \\ A. Pendekatan Penelitian}

Penelitian yang akan dilakukan adalah penelitian jenis eksperimen. Menurut Arikunto (1998) eksperimen adalah suatu cara untuk mencari sebab akibat antara dua faktor yang sengaja ditimbulkan oleh peneliti dengan mengurangi atau menyisihkan factor-faktor lain yang bisa mengganggu. Eksperimen dilakukan dengan tujuan untuk meneliti sebab akibat dengan memanipulasi satu atau dua variable pada kelompok kontrol yang tidak mengalami manipulasi.

\section{B. Rancangan Penelitian}

Penelitian merupakan eksperimen pencelupan kain katun dengan teknik jumputan menggunakan mordan tawas, kapur, dan tunjung. Desain eksperimen adalah suatu rancangan percobaan dengan tiap langkah yang benar-benar terdefinisikan sedemikian rupa, sehingga informasi yang berhubungan dengan atau diperlakukan untuk permasalahan yang sedang diteliti dapat dikumpulkan (Leksono Lestarijadi dkk,2008:40).

\section{Lokasi Penelitian}

Penelitian ini akan dilaksanakan di laboratorium Busana Jurusan Pendidikan Kesejahteraan Keluarga. Waktu pelaksanaan penelitian selama 8 bulan mulai bulan April 2013 sampai dengan bulan Nopember 2013.

\section{Subyek dan Obyek Penelitian}

Obyek penelitian ini meliputi: (1) kulit bawang merah, yaitu kulit bawang merah yang sudah kering, (2) kain kapas dan (3) Tawas, Kapur, dan Tunjung. Sedangkan Subyek penelitian ini adalah hasil berupa ketuaan warna kain jumputan.

\section{E. Teknik Pengumpulan Data}

Dalam studi eksperimen pewarnaan kain dengan teknik jumputan yang menggunaka mordan tawas dengan konsentrasi yang berbeda, peneliti 
menggunakan uji kualitas meliputi penilaian ketuaan warna dan tingkat kesukaan panelis. Peneliti menggunakan pengujian mutu hedonik, yaitu panelis diminta tanggapan tentang kesukaan produk hasil eksperimen.

Panelis yang dilibatkan dalam penelitian ini adalah sebanyak 25 orang panelis, yang terdiri dari panelis mahasiswa Tata Busana sebanyak 25 orang.

\section{F. Teknik Analisis Data}

Metode analisis data yang digunakan dalam penelitian ini ada dua yaitu analisis deskriptif dan uji statistik. Analisis deskriptif untuk mengetahui gambaran tentang data yang diperoleh yaitu ketuaan warna. Uji statistik digunakan untuk menguji hipotesis.

\section{HASIL DAN PEMBAHASAN}

A. Hasil Penelitian

1. Proses pewarnaan dengan kulit bawang merah

a. Alat dan Bahan

1) Bahan

Bahan-bahan yang digunakan dalam pewarnaan pewarnaan dan jumputan adalah: Kain katun polos warna putih, kulit bawang merah, soda abu, kapur tohor, tunjung (FeS04), tawas, bahan pengikat, bahan untuk mengisi.

\section{2) Alat-alat}

Beberapa alat yang digunakan untuk membuat motif kain dengan teknik jumputan dan proses pewarnaan adalah: Pensil, gunting, kompor dan panci, sendok kayu, dan baskom.

\section{b. Proses Ekstraksi kulir bawang merah}

Dalam melakukan proses ekstraksi/pembuatan larutan zat warna alam perlu disesuaikan dengan berat bahan yang hendak diproses sehingga jumlah larutan zat warna alam yang dihasilkan dapat mencukupi untuk mencelup bahan tekstil. Banyaknya larutan zat warna alam yang diperlukan tergantung pada jumlah bahan tekstil yang akan diproses. Perbandingan larutan zat warna dengan bahan tekstil yang biasa digunakan adalah 1: 30. Misalnya berat bahan tekstil yang diproses 100 gram maka kebutuhan larutan zat warna alam adalah 3 liter. Berikut ini adalah langkah-langkah proses ekstraksi untuk mengeksplorasi zat pewarna alam dalam skala laboratorium:

1) Keringkan dan bersihkan kulit bawang merah dari kotoran-kotorang yang tercampur pada kulit bawang merah.

2) Timbang kulit bawang merah seberat 500 gr.

3) Masukkan kulit bawang merah tersebut ke dalam panci. Tambahkan air dengan perbandingan 1:10. Contohnya jika berat bahan yang diekstrak 500gr maka airnya 5 liter.

4) Rebus bahan hingga volume air menjadi setengahnya (2,5liter). Jika menghendaki larutan zat warna jadi lebih kental volume sisa perebusan bisa diperkecil misalnya menjadi sepertiganya. Sebagai indikasi bahwa pigmen warna yang ada dalam tumbuhan telah keluar ditunjukkan dengan air setelah perebusan menjadi berwarna.

5) Saring dengan kasa penyaring larutan hasil proses ekstraksi tersebut untuk memisahkan dengan sisa bahan yang diesktrak (residu). Larutan ekstrak hasil penyaringan ini disebut larutan zat warna alam. Setelah dingin larutan siap digunakan.

\section{c. Proses Mordating}

Bahan tekstil yang hendak diwarna harus diproses mordanting terlebih dahulu. Proses mordanting ini dimaksudkan untuk meningkatkan daya tarik zat warna alam terhadap bahan tekstil serta berguna untuk menghasilkan kerataan dan ketajaman warna yang baik. Proses mordanting dilakukan sebagai berikut:

1) Potong bahan tekstil sebagai sample untuk diwarna dengan ukuran $25 \times 25$ $\mathrm{Cm}$ atau sesuai keinginan sebanyak empat lembar.

2) Untuk bahan kain kapas : Buat larutan yang mengandung 8 gram tawas dan 2 gram soda abu $\left(\mathrm{Na}_{2} \mathrm{CO}_{3}\right)$ dalam setiap 1 liter air yang digunakan. Aduk hingga larut. Rebus larutan hingga mendidih kemudian masukkan bahan kapas dan direbus selama 1jam. Setelah itu matikan api dan kain kapas dibiarkan terendam dalam larutan selama 
semalam. Setelah direndam semalaman dalam larutan tersebut, kain diangkat dan dibilas (jangan diperas) lalu dikeringkan dan disetrika. Kain kapas tersebut siap dicelup.

\section{d. Pembuatan larutan fixer (pengunci warna)}

Pada proses pencelupan bahan tekstil dengan zat warna alam dibutuhkan proses fiksasi (fixer) yaitu proses penguncian warna setelah bahan dicelup dengan zat warna alam agar warna memiliki ketahanan luntur yang baik. Ada 3 jenis larutan fixer yang biasa digunakan yaitu tunjung $\left(\mathrm{FeSO}_{4}\right)$, tawas, atau kapur tohor $\left(\mathrm{CaCO}_{3}\right)$. Untuk itu sebelum melakukan pencelupan kita perlu menyiapkan larutan fixer terlebih dengan dengan cara : Larutan fixer Tawas : Larutkan 50 gram tawas dalam tiap liter air yang digunakan. Biarkan mengendap dan ambil larutan beningnya.

\section{e. Proses Pencelupan Dengan Zat Warna Kulit Bawang merah}

Setelah bahan dimordanting dan larutan mordan siap maka proses pencelupan bahan tekstil dapat segera dilakukan dengan jalan sebagai berikut:

1) Kain diberi motif dengan menggunakan teknik jumputan

2) Siapkan larutan zat warna alam hasil proses ekstraksi dalam tempat pencelupan.

3) Masukkan bahan tekstil yang telah dijumput ke dalam larutan zat warna alam dan diproses pencelupan selama 15 - 30 menit.

4) Tiriskan dan buka ikatan tali dan kain dibilas dengan air bersih, kemudian dikeringkan di tempat yang teduh

f. Proses Fiksasi

1) Masukkan bahan 1 (bahan A) kedalam larutan mordan tawas, bahan diproses dalam larutan mordan selama 10 menit.

2) Masukkan bahan 1 (bahan B) kedalam larutan mordan kapur, bahan diproses dalam larutan mordan selama 10 menit.

3) Masukkan bahan 1 (bahan C) kedalam larutan mordan tunjung, bahan diproses dalam larutan mordan selama 10 menit.

4) Bilas dan cuci bahan lalu keringkan. Bahan telah selesai diwarnai dengan larutan zat warna alam.

2. Warna yang Dihasilkan pada Pewarnaan Kain dengan Teknik Jumputan Menggunakan Zat Warna Kulit Bawang Merah Tanpa Proses Mordatin

Pada pewarnaan kain dengan teknik jumputan yang menggunakan zat warna kulit bawang merah tanpa proses mordating didapatkan warna kecoklatan atau coklat muda. Motif jumputan yang dihasilkan tampak jelas dan proposional.

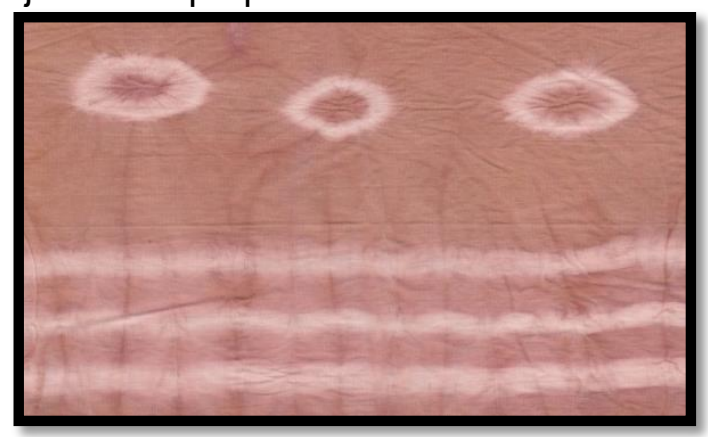

Gambar 01. Hasil Pewarnaan Jumputan Menggunakan Kulit Bawang Merah

3. Warna yang Dihasilkan pada Pencelupan Kain dengan Teknik Jumputan Menggunakan Zat Warna Kulit Bawang Merah Menggunakan Mordan Tawas, Kapur dan Tunjung

Pada pewarnaan kain dengan teknik jumputan menggunakan zat warna kulit bawang merah menggunakan mordan yang berbeda yaitu tawas, kapur dan tunjung. Dalam pencelupan menggunakan mordan tawas terjadi perubahan warna dari coklat muda menjadi kekuningan. 


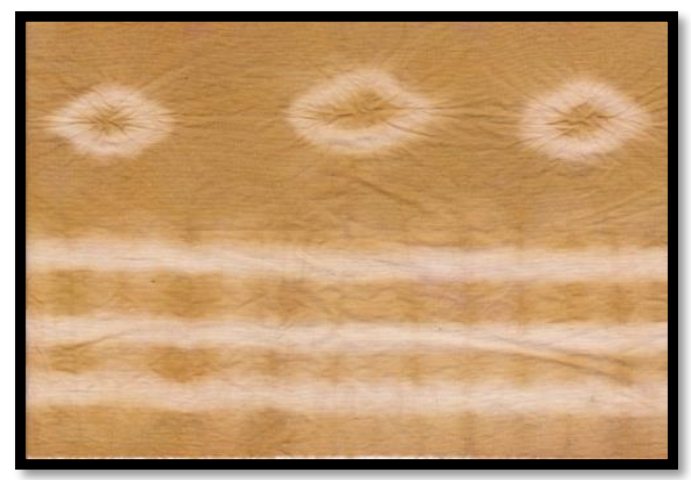

Gambar 02. Hasil Penceluban Mordan Tawas

Sedangkan pencelupan menggunakan mordan kapur tidak terjadi perubahan warna cenderung menjadi lebih muda sehingga warnanya coklat tua.

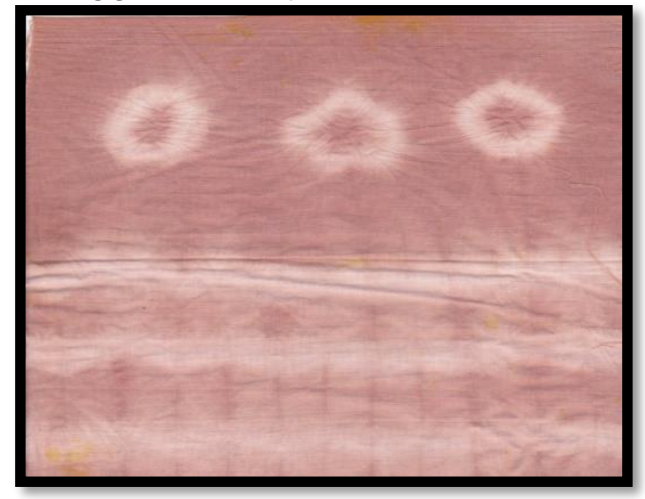

Gambar 03. Hasil Pencelupan Mordan Kapur

Pencelupan dengan mordan tunjung didaparkan warna yang lebih gelap, kain yang berwana coklat muda berubah warna menjadi coklat kehitaman.

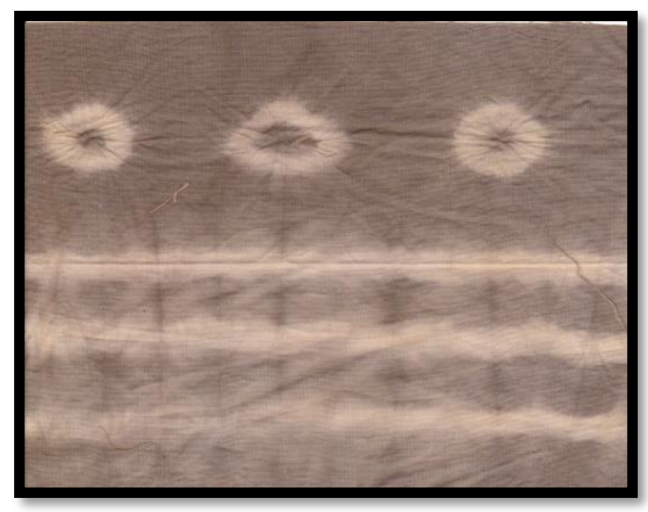

Gambar 04. Hasil Pencelupan Mordan Tunjung

Kualitas warna yang didapatkan dari para panelis bahwa penggunaan warna menggunakan mordan tawas menghasilkan warna yang lebih cerah dibandingkan menggunakan mordan kapur dan mordan tunjung. Kualitas warna yang menggunakan mordan kapur menghasilkan warna yang pudar, dan kualitas warna menggunakan mordan tunjung mendapatkan warna yang gelap dibandingkan yang lainnya.

Tabel 1 Kualitas Warna Jumputan Kualitas Hasil Jumputan

\begin{tabular}{ccc}
\hline $\begin{array}{c}\text { Tawas } \\
\text { (bahan A) }\end{array}$ & $\begin{array}{c}\text { Kapur } \\
\text { (bahan B) }\end{array}$ & $\begin{array}{c}\text { Tunjung } \\
\text { (bahan c) }\end{array}$ \\
\hline 89 & 88 & 87 \\
\hline
\end{tabular}

Tabel 2. Kualitas Hasil Jumputan

\begin{tabular}{ccc}
\hline \multicolumn{3}{c}{ Kualitas warna } \\
\hline $\begin{array}{c}\text { Tawas } \\
\text { (bahan A) }\end{array}$ & $\begin{array}{c}\text { Kapur } \\
\text { (bahan B) }\end{array}$ & $\begin{array}{c}\text { Tunjung } \\
\text { (bahan c) }\end{array}$ \\
\hline 92 & 87 & 91 \\
\hline
\end{tabular}

Dari Tabel 1 dan Tabel 2 dapat disimpulkan bahwa kualitas hasil jumputan dari segi desain motif, bentuk motif, struktur motif, ketepatan dan kerapian motif hasil jumputan yang mengunakan mordan tawas memperoleh $85 \%$ dengan kategori sangat baik, sedangkan hasil jumputan yang menggunakan mordan kapur memperoleh $88 \%$ dengan kategori sangat baik, dan hasil jumputan yang menggunakan mordan tunjung dengan nilai $87 \%$ dengan kategori sangat baik.

Sedangkan kualitas hasil jadi jumputan yang diwarna menggunakan zat warna kulit bawang merah dari segi warna yang digunakan, meratanya warna, noda dan kecerahan warna diperoleh hasil sebagai berikut, hasil jadi jumputan dengan menggunakan mordan tawas mendapat nilai $92 \%$ dengan kategori sangat baik, sedangkan hasil jadi jumputan dengan menggunakan mordan kapur mendapatkan nilai $87 \%$ dengan kategori baik, dan hasil jumputan menggunakan mordan tujnung mendapat nilai $91 \%$ dengan kategori sangat baik.

4. Hasil Jadi Pewarnaan dengan Kulit Bawang Merah yang Paling Disukai antara Menggunakan Mordan Tawas, Kapur, dan Tunjung 
Hasil pewarnaan dengan kulit bawang merah yang paling disukai anntara menggunakan mordan tawas, kapur, dan tunjung didapat dari uji panelis sebanyak 30 orang.

Tabel 3. Hasil Jadi Pewarnaan dengan Kulit Bawang Merah yang Paling Disukai antara Menggunakan Mordan Tawas, Kapur, dan Tunjung

\begin{tabular}{clcc}
\hline No & Mordan & Jumlah & $\begin{array}{c}\text { Persentase } \\
\%\end{array}$ \\
\hline 1 & $\begin{array}{l}\text { Tawas } \\
\text { (bahan A) }\end{array}$ & 13 & 52 \\
\hline 2 & $\begin{array}{l}\text { Kapur } \\
\text { (bahan B) }\end{array}$ & 2 & 8 \\
\hline 3 & $\begin{array}{l}\text { Tunjung } \\
\text { (bahan C) }\end{array}$ & 10 & 40 \\
\hline & Total & 30 & 100 \\
\hline
\end{tabular}

Dari Tabel 3 dapat dilihat bahwa hasil pewarnaan dengan kulit bawang merah yang paling disukai antara menggunakan mordan tawas, kapur, dan tunjung adalah menggunakan mordan tawas sebanyak 13 orang sekitar $52 \%$, selanjutnya adalah hasil yang menggunakan mordan tunjung sebanyak 10 orang yang menyukainya sekitas $40 \%$ sedangkan yang paling terakhir adalah hasil yang menggunakan mordan kapur sebanyak 2 orang yang menyukainnya sekitar $8 \%$.

\section{B. Pembahasan}

Dari hasil penelitian dinyatakan bahwa kulit bawang merah dapat digunakan sebagai zat pewarna tekstil dimana warna yang dihasilkan dari proses pewarnaan tersebut adalah coklat muda. Hal ini disebabkan karena kulit berwarna kecokelatan dan lapisan eksternal bawang kaya akan serat dan flavonoid, sedangkan lapisan luar yang terbuang mengandung senyawa belerang dan fructans. Kulit bawang merah mengandung zat warna alam yaitu senyawa antosianin dan flaponoida. Zat warna ini dapat diekstraksi dengan cara ekstraksi panas, dan larutan zat warna alam yang dihasilkan dapat dibuat menjadi zat warna dalam bentuk serbuk dengan proses penguapan. Zat warna yang dihasilkan dapat digunakan untuk proses pewarnaan pada bahan tekstil.

Mordan digunakan sebagai zat pembangkit warna pada pewarna alami. Bahan kimia yang digunakan adalah tunjung $\left(\mathrm{FeSO}_{4}\right)$. Tawas (Al2(SO4)3), natrium karbonat, dan kapur tohor $\left(\mathrm{CaCO}_{3}\right)$. Zat-zat mordan ini berfungsi untuk membentuk jembatan kimia antara zat warna alam dengan serat sehingga afinitas zat warna meningkat terhadap serat.

Dari hasil penelitian hasil jadi pewarnaan menggunakan kulit bawang merah yang menggunakan mordan tawas menghasilkan warna yang lebih cerah dari warna aslinya, yang semula berwarna coklat muda menjadi kekuningan. Motif jumputan yang dihasilkan juga tampak jelas. Hal ini disebabkan karena tawas yang berupa kristal putih gelap, tembus cahaya, rasanya agak asam kalau dijilat, bersifat menguatkan warna tetapi juga dapat digunakan sebagai penjernih air keruh. Selain berguna untuk mencegah lunturnya warna pada saat pencucian, mordan juga berfungsi sebagai pengarah warna, dimana kain mordan yang telah diwarnai alam, akan menghasilkan warna yang berbeda

Dari hasil penelitian hasil jadi pewarnaan menggunakan kulit bawang merah yang menggunakan mordan kapur menghasilkan warna yang lebih muda atau lebih pudar dari warna aslinya, yang semula coklat muda menjadi coklat keputihan. Hal ini disebabkan karena kapur tohor merupakan anhidrida basa, dan apabila bereaksi dengan air akan terjadi kapur padam atau kalsium hidroksida. Larutan kapur tohor mengeluarkan banyak panas, bersifat basa agak keras, dan mudah menarik gas asam arang dari udara, sehingga air mudah menjadi keruh. Larutan kapur tohor juga merupakan pengikat asam - asam nabati.

\section{PENUTUP}

\section{A. Kesimpulan}

1. Pada pewarnaan kain dengan teknik jumputan yang menggunakan zat warna kulit bawang merah tanpa proses mordating didapatkan warna 
kecoklatan atau coklat muda. Motif jumputan yang dihasilkan tampak jelas dan proposional.

2. Dalam pencelupan menggunakan mordan tawas terjadi perubahan warna dari coklat muda menjadi kekuningan. Sedangkan pencelupan menggunakan mordan kapur tidak terjadi perubahan warna cenderung menjadi lebih muda sehingga warnanya coklat tua, dan pencelupan dengan mordan tunjung didaparkan warna yang lebih gelap, kain yang berwana coklat muda berubah warna menjadi coklat kehijauan.Kualitas warna yang didapatkan dari para panelis bahwa penggunaan warna menggunakan mordan tawas menghasilkan warna yang lebih cerah dibandingkan menggunakan mordan kapur dan mordan tunjung. Kualitas warna yang menggunakan mordan kapur menghasilkan warna yang pudar, dan kualitas warna menggunakan mordan tunjung mendapatkan warna yang gelap dibandingkan yang lainnya.

3. hasil pewarnaan dengan kulit bawang merah yang paling disukai antara menggunakan mordan tawas, kapur, dan tunjung adalah menggunakan mordan tawas sebanyak 14 orang sekitar $0,47 \%$, selanjutnya adalah hasil yang menggunakan mordan tunjung sebanyak 11 orang yang menyukainya sekitas $0,37 \%$ sedangkan yang paling terakhir adalah hasil yang menggunakan mordan kapur sebanyak 5 orang yang menyukainnya sekitar $0,17 \%$.

B. Saran

1. Untuk pengerajin agar menggunakan pewarna alam yang didapat dari sisa-sisa atau limbah yang ada disekitar untuk dijadikan pewarna alternatif kain.
2. Untuk peneliti lanjut agar bisa meneliti tentang penggunaan kulit bawang perah dengan menggunakan konsentrasi mordan yang berbeda.

3. Untuk peneliti agar bisa menggunakan bahan-bahan alam yang lain untuk dijadikan zat pewarna tekstil.

\section{DAFTAR PUSTAKA}

Dian Safitri Purwaningrum, 5401402059 (2007) Pengaruh Lama Waktu Mordan Tawas terhadap Ketuaan Warna dan Kekuatan Tarik Kain Sutera dalam Proses Pewarnaan dengan Zat Warna Daun Mangga pada Busana Pesta Anak. Under Graduates thesis, Universitas Negeri Semarang

Handoyo Joko Dwi. 2008. Batik dan Jumputan. Yogyakarta. PT Mavanan Jaya Cemerlang.

Hasyim Henny. 2010. Tie Dye. Surabaya. Tiara Aksara.

Kusrianiati Dewi. 2010. Pemanfaatan Sanggon sebagai pewarna kain sutera menggunakan mordan tawas dengan konsentrasi yang berbeda. Jurnal Teknobuga. Vol.4/No2. Unnes.

Luftiati, Dewi. 2003. Pemanfaatan Kulit Bawang Merah Sebagai Bahan Pewarna Alami kain dengan Teknik Jumputan. Proseding. Seminar Nasional Produk Busana.

Rasyid Djufri. $1976 . \quad$ Teknologi pengelantangan, pencelupan dan pencapan. Bandung: Institut Teknologi Tekstil. 